\title{
Possible Consequences of a Shortage of Hydroxychloroquine for Patients with Systemic Lupus Erythematosus amid the COVID-19 Pandemic
}

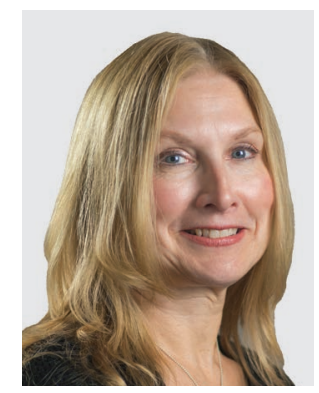

As the coronavirus disease 2019 (COVID-19; the disease caused by SARS-CoV-2) pandemic took hold in North America, rheumatology clinics across the continent were inundated with phone calls from patients with systemic lupus erythematosus (SLE) who were understandably fearful of COVID-19. One of the most common questions from patients was whether they should stop taking their medications. Since the beginning of the epidemic, turned pandemic, our immune-compromised patients with SLE have been overwhelmed with warnings of their higher risk of severe illness ${ }^{1,2}$. These statements are based on general knowledge of increased infection risk in patients with SLE, extrapolation from other viral illnesses, and expert opinion. However, adding to the confusion, there is no specific information on SLE per se or on any of the commonly used immunosuppressive drugs for $\mathrm{SLE}^{3}$. Even summary statements from those countries farther along the track of this pandemic broadly reference "patients with serious underlying disease" as being at high risk of poor outcomes without particulars ${ }^{4,5}$. Moreover, some very recent articles focus on the possible benefits of immunosuppressive drugs, both synthetic and biologic, to fight COVID-19, including early rumblings about the potential positive effect of chloroquine and hydroxychloroquine (HCQ) ${ }^{6,7}$. Then on Thursday, March 19, US President Donald Trump stated that antimalarials showed tremendous promise and "could be a game-changer." Suddenly, the rumblings became a roar. The questions about stopping HCQ turned into "I can't get HCQ, my pharmacy is out" from patients with SLE trying to access refills. All over Canada and the United States, news organizations were publishing stories of patients worried about drug supply, pharmacies documenting shortages, hospitals trying to stock up, drug companies promising to ramp up production, governments securing supply to treat patients with COVID-19 $9^{8,9}$, and even physicians stocking up for personal use ${ }^{10}$.

The benefits of antimalarials are proven for patients with SLE. In addition to managing skin and joint manifestations of SLE, antimalarials are known to prevent flares and reduce overall disease activity, reduce accrual of irreversible organ damage, reduce cardiovascular complications and throm- bosis, and improve survival ${ }^{11,12,13}$. These comprehensive benefits have led to sweeping statements by SLE experts, recommending treatment with antimalarials "starting as soon as the diagnosis is made and maintained indefinitely (unless toxicity develops), regardless of the subsequent course of lupus, including pregnancy and any additional medications needed" ${ }^{11}$. With antimalarials now touted as one of the premier weapons against the global COVID-19 pandemic, and dozens of clinical trials starting up worldwide, along with off-label use outside clinical trials, demand has skyrocketed. What effect could a shortage of HCQ have on patients with SLE who rely on the drug to manage and stabilize their disease?

The first effect will undoubtedly be an increase in worry, anxiety, and illness uncertainty. Illness uncertainty is defined as the experience of living with continuous uncertainty from a chronic illness requiring ongoing management or with a possibility of recurrence ${ }^{14,15,16}$, and is already an important concept in $\mathrm{SLE}^{15,17}$. As expected, high uncertainty is associated with high emotional distress, anxiety, and depression ${ }^{5}$, and in SLE is shown to be inversely related to health-related quality of life ${ }^{17}$. No doubt the entire world is experiencing high levels of uncertainty at present. Mental health concerns are already rising, with talk of a parallel epidemic of fear, anxiety, and depression ${ }^{18,19}$. Patients with SLE already have very high levels of comorbid anxiety and depression, which are associated with worse SLE outcomes and higher symptom burden ${ }^{20}$. Further, there is mounting evidence that psychological stress, as seen in depression and anxiety, may contribute to inflammation in SLE. The mechanisms connecting emotional stress to immune dysfunction have been previously described: stress alters immune function through changes to the hypothalamic pituitary adrenal axis, which controls the stress response and cortisol secretion. Chronic exposure to cortisol downregulates glucocorticoid receptors, leading to reduced sensitivity of immune cells to cortisol's inhibitory actions and consequently a state of chronic immune dysregulation ${ }^{21,22}$. In a study comparing 153 women with SLE to controls, serum levels of tumor necrosis factor- $\alpha$ were independently associated with both disease activity as measured by the Systemic Lupus Erythematosus

Personal non-commercial use only. The Journal of Rheumatology Copyright $(\subset) 2020$. All rights reserved. 
Disease Activity Index (SLEDAI), and mood disorders ${ }^{23}$. Pawlak, et al followed 41 female patients with SLE for 6 months and found that higher levels of daily stress were associated with increased disease activity as measured by the European Consensus Lupus Activity Measurement, and CH50 levels ${ }^{24}$. Another study of stressors over a 6-month period in 46 patients with SLE found that a high percentage of patients with SLE reported a worsening in their clinical symptomatology because of the effects of daily stress; a subset of these with more prolonged symptoms had reductions in complement levels and increased levels of dsDNA antibodies $^{25}$. A second small study found that high levels of perceived stress in patients with SLE were associated with increases in SLEDAI score 4 to 5 months later ${ }^{26}$. Could we then expect to see a surge of SLE flares as this pandemic progresses, related to the stress both of the pandemic and the disease, and compounded by fears of an HCQ shortage? Will it necessitate increased immunosuppressive medications, with an even higher risk for our patients with SLE?

There is a known risk of flare related to HCQ withdrawal. This was clearly demonstrated in the landmark study by the Canadian Hydroxychloroquine Study Group, where a randomized controlled trial of withdrawal of HCQ in patients with inactive SLE showed a 2.5-times higher risk of flare, as well as a shorter time to flare ${ }^{27}$. The extension of this study also demonstrated increased risk of major flares requiring hospitalization after HCQ withdrawal ${ }^{28}$. A more recent study similarly showed higher flare rates and a shorter duration to flare in patients with SLE discontinuing HCQ, and found an even higher risk of flare in those who have taken it for less than a year prior to discontinuation ${ }^{29}$. Low blood concentrations of HCQ have been associated with flares of SLE in the following months ${ }^{30,31}$, with nonadherence a major determinant of low blood concentrations $\mathrm{s}^{31,32}$. Studies show that HCQ provides protection from flares for 3 to 6 months following withdrawal; thus we know that some missed doses, or even a week or 2 without HCQ will not matter. However, if the pandemic goes on for months as predicted by many, and with it the shortage of HCQ, then serious SLE flares will almost certainly result. Another unanswered question is the effect of dose reductions on the risk of SLE flares. Some patients may have to reduce their dose to maintain some level of protection in the face of shortages. Indeed, in Italy, where all hospitalized patients with COVID-19 are treated with HCQ and the resultant shortage at outpatient pharmacies is widespread, patients with SLE are advised to reduce their doses to maintain some degree of coverage (personal communication). Optimal doses of HCQ are not known ${ }^{33}$, and many factors affect individual variations in blood concentration ${ }^{34,35,36}$. However, there is a clear correlation between daily dose, blood concentration, and increased disease activity with risk of flare. Longterm dose reduction for some patients may carry a risk of serious flares similar to withdrawal.
One final and ironic possibility: is it possible that one outcome may be improved adherence to HCQ by patients with SLE? Part of what makes HCQ such an attractive prospect as a treatment for COVID-19 was summarized by Dr. Didier Raoult, an author of the French study at the heart of the current furor: "It is difficult to find a product that has a better established safety profile....Furthermore its cost is negligible" ${ }^{37}$. For years, rheumatologists have been trying to convince patients with SLE of essentially the same thing. The risk-benefit ratio for HCQ is excellent, and the potential benefits significant. Yet adherence to HCQ is universally low. An early study aimed at demonstrating the relationship between blood concentrations of HCQ and clinical efficacy in patients with $\mathrm{SLE}^{30}$ found undetectable blood HCQ concentrations in a number of the patients, leading to the realization of severe nonadherence in a subset of these patients ${ }^{32}$. Since then, multiple studies have shown high levels of very poor adherence, generally ranging from $20 \%$ to $50 \%$ of patients $^{38,39,40,41,42}$. Common reasons for poor adherence cited by patients include fear of adverse effects and lack of understanding of the benefits ${ }^{32,43}$. Is it possible that part of the mad scramble at pharmacies for HCQ comes from our "legacy" patients who suddenly want to fill their previously neglected HCQ prescription? Will the positive light currently shining on antimalarials help to convince patients with SLE of the benefits? Will we see improved adherence? Only time will tell.

In the interim, rheumatologists caring for patients with SLE will need to provide reassurance if a few doses are missed, and evidence-based guidance on the use of HCQ for COVID-19, while joining the chorus of healthcare providers, patients, and advocacy groups urging protection of HCQ supply for patients with SLE.

CHRISTINE A. PESCHKEN, MD, MSc, FRCPC, University of Manitoba Arthritis Centre, Rady Faculty of Health Sciences, Winnipeg, Manitoba, Canada.

Address correspondence to Dr. C.A. Peschken, University of Manitoba, RR149 Arthritis Centre, 800 Sherbrook St., Winnipeg, Manitoba R3A 1M4, Canada. E-mail: christine.peschken@umanitoba.ca

\section{REFERENCES}

1. Centers for Disease Control and Prevention. Coronavirus disease 2019 (COVID-19): People who are at higher risk for severe illness. 2020. [Internet. Accessed April 8, 2020.] Available from: www.cdc. gov/coronavirus/2019-ncov/specific-groups/ people-at-higher-risk.html

2. American College of Rheumatology. COVID-19 frequently asked questions. 2020. [Internet. Accessed April 8, 2020.] Available from: www.rheumatology.org/Portals/0/Files/COVID-19-FAQs.pdf

3. Figueroa-Parra G, Aguirre-Garcia GM, Gamboa-Alonso CM, Camacho-Ortiz A, Galarza-Delgado DA. Are my patients with rheumatic diseases at higher risk of COVID-19? Ann Rheum Dis 2020 Mar 22 (E-pub ahead of print).

4. Wu Z, McGoogan JM. Characteristics of and important lessons from the coronavirus disease 2019 (COVID-19) outbreak in China: summary of a report of 72,314 cases from the Chinese Center for

Personal non-commercial use only. The Journal of Rheumatology Copyright $(\subset) 2020$. All rights reserved. 
Disease Control and Prevention. JAMA 2020 Feb 24 (E-pub ahead of print).

5. American College of Emergency Physicians. Guidelines for the treatment of people with COVID-19 disease. 2020. [Internet. Accessed April 8, 2020.] Available from: www.acep.org/ globalassets/images/italian-guidelines-for-covid-19-googletranslate.pdf.pdf

6. Favalli EG, Ingegnoli F, De Lucia O, Cincinelli G, Cimaz R, Caporali R. COVID-19 infection and rheumatoid arthritis: Faraway, so close! Autoimmun Rev 2020 Mar 25 (E-pub ahead of print).

7. Khan S, Siddique R, Shereen MA, Ali A, Liu J, Bai Q, et al. The emergence of a novel coronavirus (SARS-COV-2), their biology and therapeutic options. J Clin Microbiol 2020 Mar 5. (E-pub ahead of print).

8. Griffin R. Hospitals stockpile drug Trump says could treat COVID-19. Bloomberg.com (serial on the Internet). 2020. [Internet. Accessed April 8, 2020.] Available from:: www.bloomberg.com/ news/articles/2020-03-20/hospitals-stockpile-malaria-drug-trumpsays-could-treat-covid-19

9. U.S. Department of Health and Human Services. HHS accepts donations of medicine to Strategic National Stockpile as possible treatments for COVID-19 patients. [Internet. Accessed April 8, 2020.] Available from: www.hhs.gov/about/news/2020/03/29/ hhs-accepts-donations-of-medicine-to-strategic-national-stockpileas-possible-treatments-for-covid-19-patients.html

10. Sawa T. Doctors face sanctions for prescribing unproven COVID-19 drugs to friends and family, regulators warn. CBC.ca [Internet. Accessed April 8, 2020.] Available from: www.cbc.ca/news/health/ sanctions-canadian-doctors-experimental-drugs-1.5511244

11. Ruiz-Irastorza G, Ramos-Casals M, Brito-Zeron P, Khamashta MA. Clinical efficacy and side effects of antimalarials in systemic lupus erythematosus: a systematic review. Ann Rheum Dis 2010;69:20-8.

12. Costedoat-Chalumeau N, Leroux G, Piette JC, Amoura Z. Why all systemic lupus erythematosus patients should be given hydroxychloroquine treatment? Joint Bone Spine 2010;77:4-5.

13. Petri M. Lupus in Baltimore: Evidence-based 'clinical pearls' from the Hopkins Lupus Cohort. Lupus 2005;14:970-3.

14. McCormick KM. A concept analysis of uncertainty in illness. J Nurs Scholarsh 2002;34:127-31.

15. Cleanthous S, Newman SP, Shipley M, Isenberg DA, Cano SJ. What constitutes uncertainty in systemic lupus erythematosus and rheumatoid arthritis? Psychol Health 2013;28:171-88.

16. Johnson Wright L, Afari N, Zautra A. The illness uncertainty concept: a review. Curr Pain Headache Rep 2009;13:133-8.

17. Delis PC. Uncertainty and quality of life in systemic lupus erythematosus: a cross-sectional study. Rehabil Nurs 2019;44:2-10.

18. Urback R. COVID-19 could spark a mental-health tsunami. The Globe and Mail. 2020 March 24. [Internet. Accessed April 8, 2020.] Available from: www.theglobeandmail.com/opinion/ article-covid-19-could-spark-a-mental-health-tsunami

19. Yao H, Chen JH, Xu YF. Patients with mental health disorders in the COVID-19 epidemic. Lancet Psychiatry 2020;7:e21.

20. Tisseverasinghe A, Peschken C, Hitchon C. Anxiety and mood disorders in systemic lupus erythematosus: current insights and future directions. Curr Rheumatol Rep 2018;20:85.

21. Morand EF. Systemic lupus erythematosus: stress and the onset of SLE. Nat Rev Rheumatol 2018;14:127-8.

22. Tosevski DL, Milovancevic MP. Stressful life events and physical health. Curr Opin Psychiatry 2006;19:184-9.

23. Postal M, Lapa AT, Sinicato NA, de Oliveira Pelicari K, Peres FA, Costallat LT, et al. Depressive symptoms are associated with tumor necrosis factor alpha in systemic lupus erythematosus. J Neuroinflammation 2016;13:5.

24. Pawlak CR, Witte T, Heiken H, Hundt M, Schubert J, Wiese B, et al. Flares in patients with systemic lupus erythematosus are associated with daily psychological stress. Psychother Psychosom 2003;72:159-65.

25. Peralta-Ramirez MI, Jimenez-Alonso J, Godoy-Garcia JF, Perez-Garcia M. The effects of daily stress and stressful life events on the clinical symptomatology of patients with lupus erythematosus. Psychosom Med 2004;66:788-94.

26. Jung JY, Nam JY, Kim HA, Suh CH. Elevated salivary alpha-amylase level, association between depression and disease activity, and stress as a predictor of disease flare in systemic lupus erythematosus: a prospective case-control study. Medicine 2015;94:e1184.

27. Canadian Hydroxychloroquine Study Group. A randomized study of the effect of withdrawing hydroxychloroquine sulfate in systemic lupus erythematosus. N Engl J Med 1991;324:150-4.

28. Tsakonas E, Joseph L, Esdaile JM, Choquette D, Senecal JL, Cividino A, et al. A long-term study of hydroxychloroquine withdrawal on exacerbations in systemic lupus erythematosus. The Canadian Hydroxychloroquine Study Group. Lupus 1998;7:80-5.

29. Aouhab Z, Hong H, Felicelli C, Tarplin S, Ostrowski RA. Outcomes of systemic lupus erythematosus in patients who discontinue hydroxychloroquine. ACR Open Rheumatol 2019;1:593-9.

30. Costedoat-Chalumeau N, Amoura Z, Hulot JS, Hammoud HA, Aymard G, Cacoub P, et al. Low blood concentration of hydroxychloroquine is a marker for and predictor of disease exacerbations in patients with systemic lupus erythematosus. Arthritis Rheum 2006;54:3284-90.

31. Mok CC, Penn HJ, Chan KL, Tse SM, Langman LJ, Jannetto PJ. Hydroxychloroquine serum concentrations and flares of systemic lupus erythematosus: a longitudinal cohort analysis. Arthritis Care Res 2016;68:1295-302.

32. Costedoat-Chalumeau N, Amoura Z, Hulot JS, Aymard G, Leroux G, Marra D, et al. Very low blood hydroxychloroquine concentration as an objective marker of poor adherence to treatment of systemic lupus erythematosus. Ann Rheum Dis 2007;66:821-4.

33. Melles RB, Jorge AM, Marmor MF, Zhang Y, Choi HK. Sharp decline in hydroxychloroquine dosing-analysis of 17,797 initiators from 2007 to 2016. Clin Rheumatol 2018;37:1853-9.

34. Jallouli M, Galicier L, Zahr N, Aumaitre O, Frances C, Le Guern $\mathrm{V}$, et al. Determinants of hydroxychloroquine blood concentration variations in systemic lupus erythematosus. Arthritis Rheum 2015;67:2176-84.

35. Lee JY, Vinayagamoorthy N, Han K, Kwok SK, Ju JH, Park KS, et al. Association of polymorphisms of cytochrome p450 2d6 with blood hydroxychloroquine levels in patients with systemic lupus erythematosus. Arthritis Rheum 2016;68:184-90.

36. Yeon Lee J, Lee J, Ki Kwok S, Hyeon Ju J, Su Park K, Park SH. Factors related to blood hydroxychloroquine concentration in patients with systemic lupus erythematosus. Arthritis Care Res 2017;69:536-42.

37. Colson P, Rolain JM, Raoult D. Chloroquine for the 2019 novel coronavirus SARS-COV-2. Int J Antimicrob Agents 2020;55:105923.

38. Liu LH, Fevrier HB, Goldfien R, Hemmerling A, Herrinton LJ. Understanding nonadherence with hydroxychloroquine therapy in systemic lupus erythematosus. J Rheumatol 2019;46:1309-15.

39. Costedoat-Chalumeau N, Galicier L, Aumaitre O, Frances C, Le Guern V, Liote F, et al. Hydroxychloroquine in systemic lupus erythematosus: results of a French multicentre controlled trial (PLUS Study). Ann Rheum Dis 2013;72:1786-92.

40. Feldman CH, Collins J, Zhang Z, Subramanian SV, Solomon DH, Kawachi I, et al. Dynamic patterns and predictors of hydroxychloroquine nonadherence among Medicaid beneficiaries with systemic lupus erythematosus. Semin Arthritis Rheum 2018;48:205-13.

41. Lee SG, Park EK, Park JH, Kweon SM, Kim YK, Kim GT.

Personal non-commercial use only. The Journal of Rheumatology Copyright $\subset$ 2020. All rights reserved. 
Compliance and persistence with hydroxychloroquine in South Korean patients with systemic lupus erythematosus. Lupus 2018;27:753-61.

42. Iudici M, Pantano I, Fasano S, Pierro L, Charlier B, Pingeon $\mathrm{M}$, et al. Health status and concomitant prescription of immunosuppressants are risk factors for hydroxychloroquine non-adherence in systemic lupus patients with prolonged inactive disease. Lupus 2018;27:265-72.
43. Cabral RTS, Klumb EM, Carneiro S. Patients opinion and adherence to antimalarials in lupus erythematosus and rheumatoid arthritis treatment. J Dermatolog Treat 2020;31:264-9.

First Release May 1 2020; J Rheumatol 2020;47:787-90; doi:10.3899/jrheum.200395 